\title{
The Immunomodulatory Imbalance in Patients with Ketamine Cystitis
}

\author{
Gang-Yi Fan, ${ }^{1}$ Juin-Hong Cherng, ${ }^{2}$ Shu-Jen Chang, ${ }^{3}$ \\ Raju Poongodi, ${ }^{2}$ Adrienne Chang, ${ }^{4}$ Sheng-Tang Wu, ${ }^{5}$ and En Meng ${ }^{5}$ \\ ${ }^{1}$ Graduate Institute of Medical Sciences, National Defense Medical Center, Taipei, Taiwan \\ ${ }^{2}$ Department of Biology and Anatomy, National Defense Medical Center, Taipei, Taiwan \\ ${ }^{3}$ Faculty of Dentistry, School of Dentistry, National Yang-Ming University, Taipei, Taiwan \\ ${ }^{4}$ Department of Chemistry, New York University Abu Dhabi, Abu Dhabi, UAE \\ ${ }^{5}$ Division of Urology, Department of Surgery, Tri-Service General Hospital, National Defense Medical Center, Taipei, Taiwan
}

Correspondence should be addressed to En Meng; en.meng@gmail.com

Received 30 July 2017; Accepted 26 September 2017; Published 24 October 2017

Academic Editor: Robert Stoehr

Copyright (C) 2017 Gang-Yi Fan et al. This is an open access article distributed under the Creative Commons Attribution License, which permits unrestricted use, distribution, and reproduction in any medium, provided the original work is properly cited.

\begin{abstract}
The pathogenesis of ketamine cystitis (KC) has been recently linked with immune response to patients but the same has not yet been established. Hence, this study aims to propose a possible immune mechanism of irreversible bladder damage caused by KC. A total of $53 \mathrm{KC}$ patients and 21 healthy volunteers as controls have been retrospectively assessed. The levels of serum immunoglobulin E (IgE), IL-6, and IFN- $\gamma$ of KC patients were significantly higher than those of controls, whereas the TGF- $\beta$ levels of KC patients substantially reduced but the IL-2 and IL- 4 levels of KC patients were comparable to those of controls. Moreover, the KC patients had significantly higher counts of $\mathrm{T}_{\mathrm{H}} 1, \mathrm{~T}_{\mathrm{H}} 2$, and $\mathrm{T}_{\mathrm{H}} 17$ cells than those of controls. The immune response of $\mathrm{KC}$ users may begin with the IL- 6 production and differentiation of $\mathrm{T}_{\mathrm{H}} 17$ and may be followed by alternating between high expressions of $\mathrm{T}_{\mathrm{H}} 1$ and $\mathrm{T}_{\mathrm{H}} 2$. The IL-6 may further suppress the $\mathrm{T}_{\mathrm{REG}}$ cells which can aggravate chronic inflammation in KC patients and the imbalance in $\mathrm{T}_{\mathrm{H}} 17$ and $\mathrm{T}_{\mathrm{REG}}$ cells may involve the pathogenesis of $\mathrm{KC}$. Further investigation is needed to define the role of IL- 6 in $\mathrm{T}_{\mathrm{H}} 1 / \mathrm{T}_{\mathrm{H}} 2 / \mathrm{T}_{\mathrm{H}} 17$-regulated signaling pathway in ketamine-induced cystitis.
\end{abstract}

\section{Introduction}

Ketamine is a phencyclidine hydrochloride derivative which is mainly used for starting and maintaining anesthesia [1]. It induces a dissociative, trance-like state in which the patient is unable to respond to external stimuli [2]. Chronic abuse has been associated with an out-of-body experience known as the K-hole phenomenon [3]. Due to low price and availability, ketamine has been increasingly used as a recreational drug which affects the central nervous and cardiovascular systems [4]. The chronic ketamine abuse may cause ulcerative cystitis and dysfunction of the lower urinary tract, both of which have been recognized as a new disease entity, called "ketamine cystitis" (KC). The number of KC patients has been increased dramatically in the past decade [5]. The KC shares many common histopathological features with interstitial cystitis/bladder pain syndrome (IC/BPS), including urothelial ulceration, inflammatory cell infiltration, and varying degrees of bladder wall fibrosis [6]. Among them, the long-term bladder inflammation may cause fibrosis of the bladder wall and, eventually, a contracted bladder [7]. In particular, the eosinophil and mast cell infiltration are frequently seen in human bladder tissue after long-term ketamine use $[6,8,9]$. A recent study reported that the KC patients had higher serum immunoglobulin E (IgE) than patients with IC/BPS or acute bacterial cystitis, which may be associated with bladder pain severity and small maximal bladder capacity in KC patients [10]. Therefore, the immune response to ketamine may play a key role in the pathogenesis of KC. However, only little knowledge on the immune activity in $\mathrm{KC}$ patients has been established.

On the other hand, the pivotal immune events of immune diseases are the development of antigen-specific effector $\mathrm{T}$ helper type $2\left(\mathrm{~T}_{\mathrm{H}} 2\right)$ cells, $\mathrm{T}_{\mathrm{H}} 1$ cells, or the recently defined 
$\mathrm{T}_{\mathrm{H}} 17$ cells that are associated with clinical features and disease progression [11]. It is known that the phenotype of $\mathrm{T}$ cells is influenced by the tissue microenvironment which is produced through the dominant kind of cytokines, costimulatory molecules, and the character and dose of antigen presented. The $\mathrm{T}_{\mathrm{H}} 1$ cell development is promoted by interleukin 12 (IL-12) and gamma interferon (IFN- $\gamma$ ) and primarily involves T-bet signaling. The generation of $\mathrm{T}_{\mathrm{H}} 2$ cells is probably induced by IL-4, IL-5, and IL- 6 costimulation. The $\mathrm{T}_{\mathrm{H}} 17$ lineage is induced by the secretion of IL-6, IL-21, and the transforming growth factor beta (TGF- $\beta$ ), whereas the $\mathrm{T}_{\mathrm{H}} 17$ cells secrete a profile of potent proinflammatory cytokines (IL-17, IL-21, and IL-22), potent tumor necrosis factor $\alpha$ (TNF- $\alpha$ ), and IL- 6 upon certain stimulation [12]. It is to be noted that the regulatory $\mathrm{T}$ ( $\mathrm{T}_{\mathrm{REG}}$ ) cells secrete IL-10 and TGF- $\beta$, which modulates helper T cell activity and suppresses some of their functions, inducing tolerance to antigens.

The $\mathrm{T}_{\mathrm{H}} 1, \mathrm{~T}_{\mathrm{H}} 2$, and $\mathrm{T}_{\mathrm{H}} 17$ populations, and the cytokines they release, are antagonistic to each other and one or the other subtype is dominant in response to a particular pathogen at any one time. However, it is important to know how the body determines, and which differentiation pattern and immune response are appropriate for a specific pathogen, and what the molecular mechanisms that underpin differentiation into a $T_{H} 1$, a $T_{H} 2$, or a $T_{H} 17$ cell are [13]. Since the contribution of specific $\mathrm{T}_{\mathrm{H}}$ cell subsets and related cytokines in the pathogenesis of $\mathrm{KC}$ is unknown, we hypothesize that measuring circulating cytokines may elucidate the imbalance between $\mathrm{T}_{\mathrm{H}}$ cell subsets in KC patients. In this context, we conducted this case-control study in order to investigate plasma levels of $\mathrm{T}_{\mathrm{H}} 1$ (IL-2, IFN- $\gamma$ ), $\mathrm{T}_{\mathrm{H}} 2$ (IL-4, IL-5), $\mathrm{T}_{\mathrm{H}} 17$ (IL$17)$, and $\mathrm{T}_{\mathrm{REG}}$ (TGF- $\beta$ ) cytokines.

\section{Materials and Methods}

2.1. Patient and Sample Collection. A total of $53 \mathrm{KC}$ patients and 21 healthy volunteers were included in this retrospective study. Each of the KC patients showed symptoms of lower urinary tract irritation, such as urgency, nocturia, and frequency. The urine and blood samples of each patient were collected for analysis. The urine test panel was conducted for $\mathrm{pH}$ and sediments which include urine red blood cells (RBCs), urine white blood cells (WBCs), and epithelial cells. Blood analysis included WBC counts, RBC counts, and differential count (neutrophils, lymphocytes, monocytes, and eosinophils). The paraffin-embedded urothelial tissues were obtained by urothelial biopsy from six patients under sterile conditions after one week of the urine and blood sample collection.

2.2. Histological Analysis. The paraffinized sections $(0.6 \mu \mathrm{m})$ of each patient (3-10 sections/patient) were stained with Gill's hematoxylin V (MUTO, Tokyo, Japan) and 1\% eosin alcohol solution (MUTO; H\&E). The obtained H\&E slides were examined under a light microscope (Olympus BX51; Olympus, Tokyo, Japan).

2.3. Serum Cytokine Assay. The serum samples were collected and the production of cytokine/chemokines was quantified by the MILLIPLEX ${ }^{\text {TM }}$ MAP Human Cytokine/Chemokine Kit (Millipore Corp., Billerica, MA). Serum specimens were drawn from $21 \mathrm{KC}$ patients (13 males, 8 females) and 21 volunteers (17 males, 4 females). Eight-parameter logistic standard curves were set and data were processed with MILLIPLEX ${ }^{\circledR}$ Analyst 5.1 software. The cytokines levels IL-1, IL-2, IL-4, IL5 , IL- 6 , IL-17, TNF- $\alpha$, IFN- $\gamma$, TGF- $\beta 1$, TGF- $\beta 2$, and TGF$\beta 3$ were analyzed by enzyme-linked immunosorbent assay (ELISA).

2.4. $T_{H} 1 / T_{H} 2 / T_{H} 17$ Determination in Peripheral Blood Mononuclear Cells (PBMCs). Peripheral blood was collected from $13 \mathrm{KC}$ patients (10 males, 3 females) and 13 volunteers (10 males, 3 females) by venous puncture and collected into preservative-free heparin. The PBMCs were isolated by means of Ficoll-Plaque Plus density gradient centrifugation (Amersham Biosciences, NJ, USA). For intracellular staining, PMBCs at a concentration of 1-10 million cells $/ \mathrm{mL}$ were stained for $5 \mathrm{~h}$ with phorbol 12-myristate 13-acetate (PMA)/ionomycin at $50 \mathrm{ng} / \mathrm{mL}$ and $1 \mu \mathrm{g} / \mathrm{mL}$, respectively. $4 \mu \mathrm{L}$ of BD GolgiStop ${ }^{\mathrm{TM}}$ was added for every $6 \mathrm{~mL}$ of cell culture and mixed thoroughly. The PBMCs were then fixed in BD Cytofix ${ }^{\mathrm{TM}}$ Fixation Buffer and made permeable with BD Phosflow ${ }^{\mathrm{TM}}$ Perm/Wash Buffer. The percentages of $\mathrm{T}_{\mathrm{H}} 1$ and $\mathrm{T}_{\mathrm{H}} 2$ in $\mathrm{CD}^{+} \mathrm{T}$ cells were obtained through flow-cytometric analysis using the $\mathrm{BD}$ Human $\mathrm{T}_{\mathrm{H}} 1 / \mathrm{T}_{\mathrm{H}} 2 / \mathrm{T}_{\mathrm{H}} 17$ Phenotyping Kit, which has a four-color cocktail of fluorescent antibodies specific for Human CD4 (PERCP-CY5.5 Clone: SK3), IFN- $\gamma$ (for $\mathrm{T}_{\mathrm{H}} 1$, FITC Clone: B27), IL-4 (for $\mathrm{T}_{\mathrm{H}} 2$, APC Clone: MP425D2), and IL-17A (for $\mathrm{T}_{\mathrm{H}}$ 17, PE Clone: N49-653).

2.5. Statistical Analysis. All the data were evaluated by analysis of variance (Sigma plot, 2001). The values are reported as mean $\pm \mathrm{SD}$ of at least three experiments. Paired $t$-test and chi-square test were employed for comparison between two groups, and $p$ values $\leq 0.05$ were considered statistically significant. The correlation coefficient $(r)$ was applied between the serum cytokine levels.

\section{Results}

A total of 74 subjects (53 KC users and 21 nonusers) were enrolled in this study. The chronic ketamine users are 31 males and 22 females in which their age was $23.84 \pm$ 4.74 years (mean $\pm \mathrm{SD}$ ). The average duration of ketamine usage was $50.44 \pm 4.99$ months for KC patients (Table 1). Among the $53 \mathrm{KC}$ patients, 26 patients underwent full clinical examination and cystoscopy with hydrodistention, and 3 patients refused bladder biopsy. Table 2 lists the clinical information and serum Ig levels. The laboratory studies revealed an elevated creatinine $(1.25 \pm 0.42 \mathrm{mg} / \mathrm{dL})$ and $\operatorname{IgE}$ levels $(261.59 \pm 56.03 \mathrm{IU} / \mathrm{mL})$ with positive RBCs and WBCs in urine analysis. Further, the urothelial biopsies were performed a week after urine and blood sample collection. And, the tissue histology analyzed using hematoxylin and eosin (H\&E) stain. The urinary bladder mucosa revealed denuded bladder epithelium, hemorrhage (Figures 1(a) and 1(c)), acute and chronic inflammation as well as the presence of 
TABLE 1: Demographic and laboratory characteristics of KC patients. * SD: standard deviation. The normal range of each characteristic is obtained from Department of Clinical Pathology, Tri-Service General Hospital, Taipei, Taiwan.

\begin{tabular}{lccc}
\hline Characteristic & $\begin{array}{c}n, n(\%) \text { or } \\
\text { mean } \\
(\mathrm{SD})^{*}\end{array}$ & Unit & Normal range \\
\hline Male : female ratio & $31: 22$ & & - \\
Age, years & $23.84(4.74)$ & & - \\
Duration of ketamine & $50.44(4.99)$ & & - \\
abuse, months & $9.32(0.45)$ & $10 \times 3 / \mathrm{uL}$ & $4.50-11.00$ \\
WBC & $63.28(1.5)$ & $\%$ & $40.0-74.0$ \\
Neutrophil & $25.71(1.15)$ & $\%$ & $19.0-48.0$ \\
Lymphocyte & $6.34(0.37)$ & $\%$ & $3.4-9.0$ \\
Monocyte & $4.11(0.77)$ & $\%$ & $0.0-7.0$ \\
Eosinophil & $6.31(0.1)$ & - & $5.0-8.0$ \\
pH & $6.87(2.168)$ & $\mathrm{HPF}$ & $0-5$ \\
Urine RBC & $16.11(4)$ & $\mathrm{HPF}$ & $0-5$ \\
Urine WBC & $5.4(1.91)$ & $\mathrm{HPF}$ & $0-6$ \\
Epithelial cells & $1.25(0.42)$ & $\mathrm{mg} / \mathrm{dL}$ & $0.5-0.9$ \\
Creatinine & & &
\end{tabular}

TABLE 2: Serum complement and immunoglobulin tests of KC patients. The normal range of each characteristic is obtained from Department of Clinical Pathology, Tri-Service General Hospital, Taipei, Taiwan.

\begin{tabular}{lccc}
\hline Characteristic & $\begin{array}{c}n, n(\%) \text { or } \\
\text { mean } \\
(\mathrm{SD})^{*}\end{array}$ & Unit & Normal range \\
\hline $\mathrm{C} 3$ & $96.48(4.59)$ & $\mathrm{mg} / \mathrm{dL}$ & $79.0-152.0$ \\
C4 & $20.37(1.01)$ & $\mathrm{mg} / \mathrm{dL}$ & $16.0-38.0$ \\
Immunoglobulin G & $927.57(51.48)$ & $\mathrm{mg} / \mathrm{dL}$ & $751-1560$ \\
Immunoglobulin M & $108.86(14.6)$ & $\mathrm{mg} / \mathrm{dL}$ & $46-304$ \\
Immunoglobulin E & $261.59(56.03)$ & $\mathrm{IU} / \mathrm{mL}$ & $<165.0$ \\
\hline
\end{tabular}

${ }^{*} P<0.05$.

eosinophil, eosinophil infiltrates, and fibrosis deposition over submucosa; the stroma revealed intravascular neutrophil and eosinophil accumulation (magnified view from black box, Figures 1(b) and 1(d)).

Flow-cytometric analysis of KC patients showed considerably higher $\mathrm{T}_{\mathrm{H}} 1(\mathrm{IFN}-\gamma, 10.94 \pm 1.81 \%), \mathrm{T}_{\mathrm{H}} 2$ (IL-4, $10.72 \pm$ $2.79 \%$, and IL-5, $11.09 \pm 4.17 \%$ ), and $\mathrm{T}_{\mathrm{H}} 17$ (IL-17A, $7.11 \pm$ $2.12 \% ; p=0.0001$ ) cells and also gave some representative fluorescence-activated cell sorting (FACS) plots (Figure 2). The univariate comparison of 6 cytokines in the normal and $\mathrm{KC}$ groups revealed a two- to ninefold increase in serum IL-6 (2-tailed $p=0.05$ ), IL-1 $\beta$, IL-5, and IL-17 expression. The serum levels of the remaining proteins, namely, IL-2 and IL-4, were not significantly increased in the KC group relative to control groups (Figure 3(a)). The distribution of all serum cytokines tested passed the Mann-Whitney $U$ test for normality. In addition, the serum cytokine assays were used to determine the effects of ketamine on inflammatory cytokine levels which showed a remarkably increased level of TNF- $\alpha$ (KC versus control; $193.59 \pm 282.17$ versus $98.43 \pm$ $85.48 \mathrm{pg} / \mathrm{mL})$ and IFN- $\gamma(369.78 \pm 564.56$ versus $0 \mathrm{pg} / \mathrm{mL}$; $p<0.001$ ) in KC cases (Figure 3(b)).

Patients with KC had significant decrease in TGF- $\beta 1$ (KC versus control; $=25429.14 \pm 25940.15$ versus $38857.60 \pm$ $13482.19 \mathrm{pg} / \mathrm{mL} ; p=0.008)$ and TGF- $\beta 3$ (950.01 \pm 498.500 versus $1236.30 \pm 218.88 \mathrm{pg} / \mathrm{mL} ; p=0.046$; Mann-Whitney $U$ test) levels (Figure 3(c)). The TGF- $\beta 2$ level was also found to lower in KC patients comparing to the controls (1068.22 \pm 695.280 versus $1380.99 \pm 387.45 \mathrm{pg} / \mathrm{mL} ; p=0.093$ ) although there was no significance. Since the $\mathrm{KC}$ group revealed that the levels of TGF- $\beta 1$, TGF- $\beta 2$, TGF- $\beta 3$ were below the level of detection in the control group, these results lend support to our hypothesis that an increase in cytokines is linked to inflammatory cells and regulation between $\mathrm{T}_{\mathrm{H}} 1, \mathrm{~T}_{\mathrm{H}} 2$, and $\mathrm{T}_{\mathrm{H}} 17$.

The basis of several statistical tests that result in a correlation coefficient is defined as a numerical representation of the strength and direction of a relationship. On moving to the correlation of cytokines of KC patients (Figure 4), the IL6 was positively correlated with IL-4 $(r=0.414, p<0.05)$, and IL-1 $\beta$ and the IL-17 were positively correlated with IL-5 $(r=0.939, p<0.001$ and $r=0.840, p<0.001)$. Further, the TNF- $\alpha$ and IFN- $\gamma$ were positively correlated with IL-1 $\beta$ $(r=0.831, p<0.001$ and $r=0.804, p<0.001)$, and TNF- $\alpha$ and IFN- $\gamma$ were positively correlated with IL-17 $(r=0.692$, $p<0.001$ and $r=0.769, p<0.001)$. Moreover, a direct correlation was found in TNF- $\alpha$ with IFN- $\gamma(r=0.692$, $p<0.001)$ and IL-6 with IL-2 $(r=0.447, p<0.01)$. But, IL-6 with IL- 4 and IL- 6 with IL-2 have found very least correlation in this study.

\section{Discussion}

In the current study, we have illustrated the different profiles of inflammatory cytokines and $\mathrm{T}_{\mathrm{H}}$ cell expression in KC patients versus healthy controls. The differing cytokine characteristics between normal control and chronic ketamine users may allude to a possible mechanism of KC (Figure 5). In this regard, we hypothesize that the acute inflammation seen in the bladder mucosal and submucosal layer may be caused by the acute immune response of ketamine through the $\mathrm{T}_{\mathrm{H}} 1$ cell pathway. Ketamine may enhance the production of IL- 6 which can further result in the apoptosis and shedding of epithelial and interstitial cells. In KC patients, $\mathrm{T}_{\mathrm{H}} 1$ and $\mathrm{T}_{\mathrm{H}} 2$ cells may be produced in a positive feedback loop from naïve $\mathrm{T}$ cells and then inhibit each other; the immune response oscillates between $\mathrm{T}_{\mathrm{H}} 1$ and $\mathrm{T}_{\mathrm{H}} 2$ cells, triggering varying symptoms and eosinophil infiltration among chronic ketamine users.

Further, we found significantly increased levels of IL-6, TNF- $\alpha$, and IFN- $\gamma$ with comparably higher levels of IL- $1 \beta$, IL-5, and IL-17 in the serum of KC patients than those of the healthy controls. Since the cytokine, IL-6, promotes the development of $\mathrm{T}_{\mathrm{H}} 17$ cells, the higher level of IL- 6 in KC patients suggests that the balance between $\mathrm{T}_{\mathrm{H}} 17$ and $\mathrm{T}_{\mathrm{H}} 1$ responses as well as IL- 6 production is dysregulated in $\mathrm{KC}$, which resulted in the reinforced feedback that increases the IL-1 $\beta$ and IL-17 


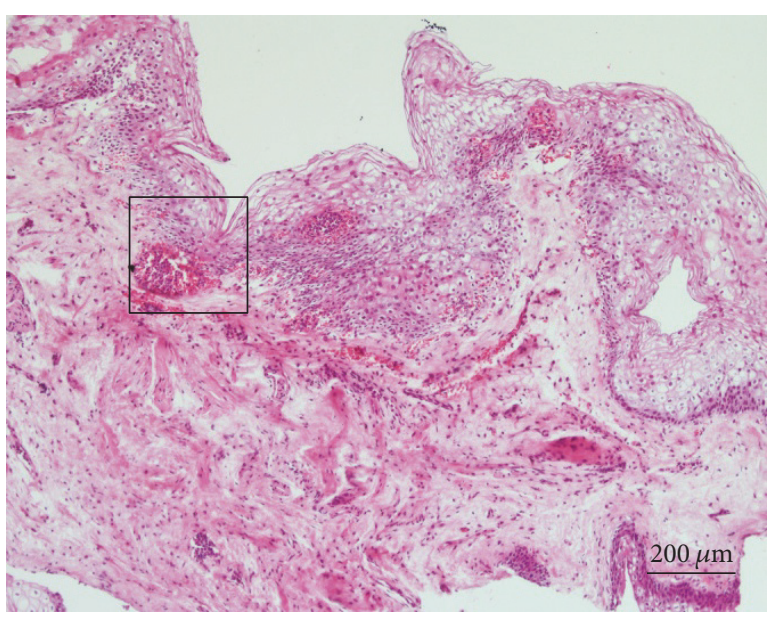

(a)

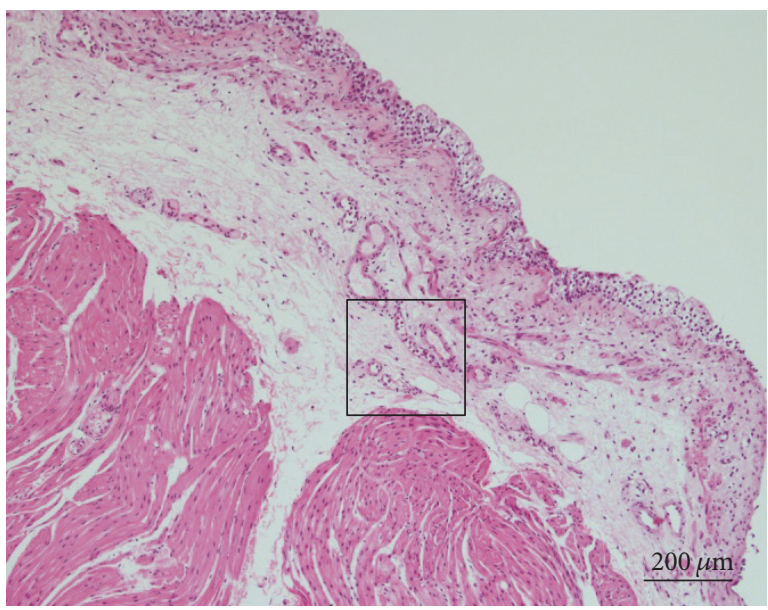

(c)

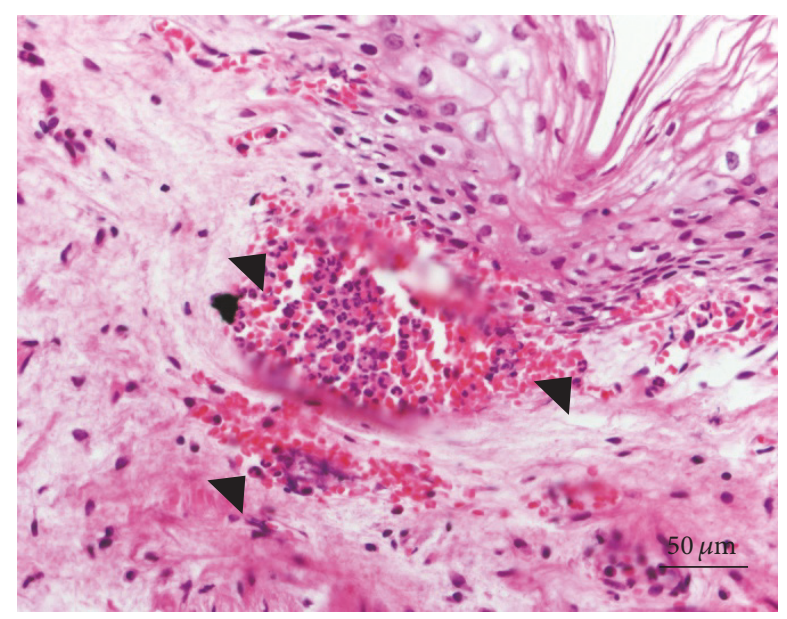

(b)

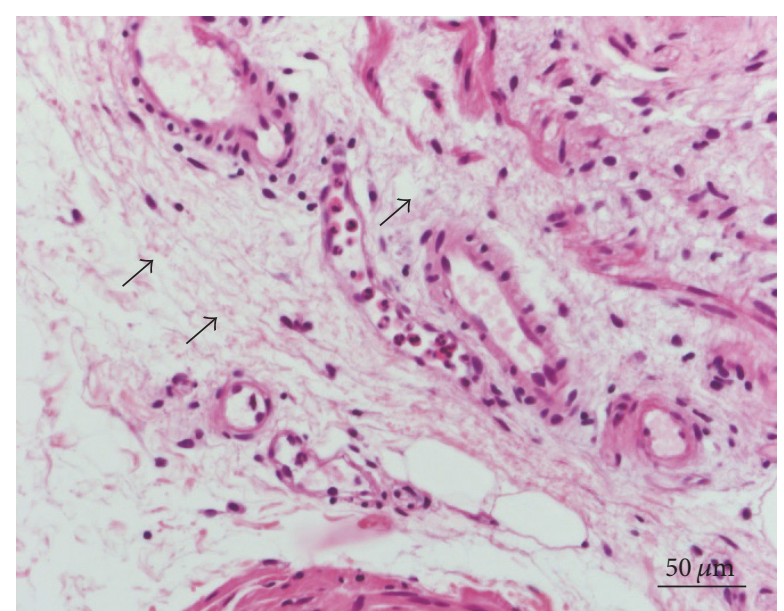

(d)

FIGURE 1: Histological analysis of urothelial bladder biopsy in ketamine cystitis patients stained with hematoxylin and eosin demonstrating. (a, b) Neutrophils and eosinophils infiltrates in suburothelium and (c, d) fibrosis deposition (magnification, 100x). The stroma of urothelial bladder biopsy (b) and (d) designated by the black boxed section in (a) and (c), respectively (magnification, 400x). The arrow denotes "neutrophils and eosinophils infiltrates" and "fibrosis deposition" in Figure 1(b) and Figure 1(d), respectively.

production in $\mathrm{CD} 4+\mathrm{T}$ cells. This increase may contribute to disease pathogenesis (Figure 5). Therefore, the function of IL-6 might assist in the knowledge of its complex role in inflammation: throughout acute inflammation, the IL-6 might favor the resolution from neutrophilic infiltrate as well as favor the initiation from the immune response in chronic inflammation. Further, the IL- 6 induces the development of $\mathrm{T}_{\mathrm{H}} 17$ cells from naïve $\mathrm{T}$ cells and, together with TGF- $\beta$, may boost the mononuclear-cell infiltrate and take part in disease pathogenesis [14].

$\mathrm{T}_{\mathrm{REG}}$ cells have been recognized as a suppressor of effector $\mathrm{T}$ cells and, thus, are thought to control the $\mathrm{T}_{\mathrm{H}} 1, \mathrm{~T}_{\mathrm{H}} 2$, and $\mathrm{T}_{\mathrm{H}} 17$ responses. Our results showed low concentration of $\mathrm{T}_{\mathrm{REG}}$ related serum cytokines, IL- 2 and TGF- $\beta$, which may explain the persistent inflammation in the KC patients (Figures $3(\mathrm{a})$ and $3(\mathrm{c})$ ). It is to be noted that the TGF- $\beta 3$ regulates molecules involved in cellular adhesion and extracellular matrix (ECM) formation in tissue [15]. So, the lower concentration of TGF- $\beta 3$ in the KC group suggests the impaired healing capability of bladder epithelial lining in chronic KC patients. The elevated IL-17 level and reduced TGF- $\beta$ level showed that the CD4+ T cell differentiation is biased away from $T_{R E G}$ cells toward the $T_{H} 17$ cell phenotype [16]. The differentiation of $\mathrm{CD}^{+}$cells generates the $\mathrm{T}_{\mathrm{H}} 1$ and $\mathrm{T}_{\mathrm{H}} 2$ phenotypes with the same receptor specificity, indicating the competition for antigenic stimulation, mediated by antigenpresenting cells (APCs), combined with cytokine-mediated cross-suppression between phenotypes to yield a response that is eventually dominated by $\mathrm{T}$ helper cells that are uniform in both receptor specificity and cytokine secretion phenotype. We found a different $\mathrm{T}$ helper cell phenotype distribution that the $\mathrm{T}_{\mathrm{H}} 1, \mathrm{~T}_{\mathrm{H}} 2$, and $\mathrm{T}_{\mathrm{H}} 17$ receptors were all expressed in PBMCs (Figure 2), consistent with recent data [17]. We subsequently analyzed the serum cytokine secreted from the T helper cells in KC patients.

Previous studies have shown that many, but not all, of the effects of IFN- $\gamma$ paracrine can be stimulated to $\mathrm{T}_{\mathrm{H}} 1$ cells to secrete lymphokines [18]. The increase in IFN- $\gamma$ 


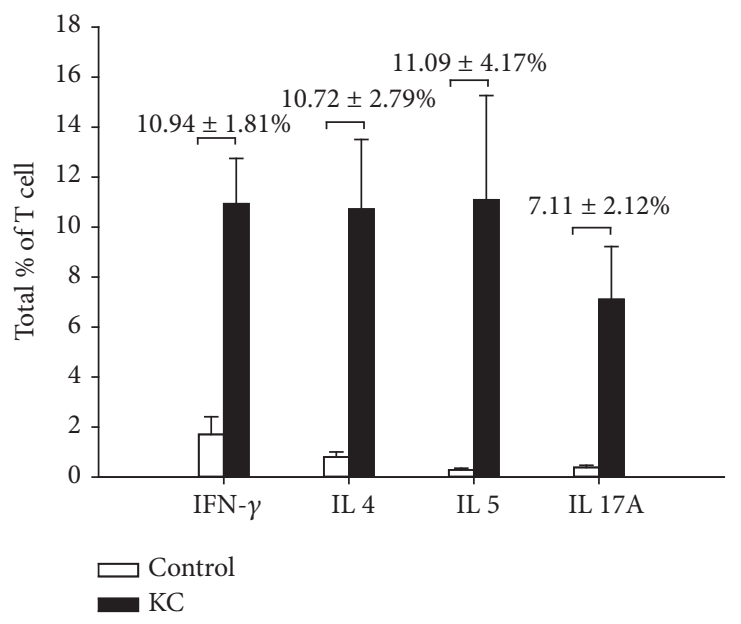

(a)
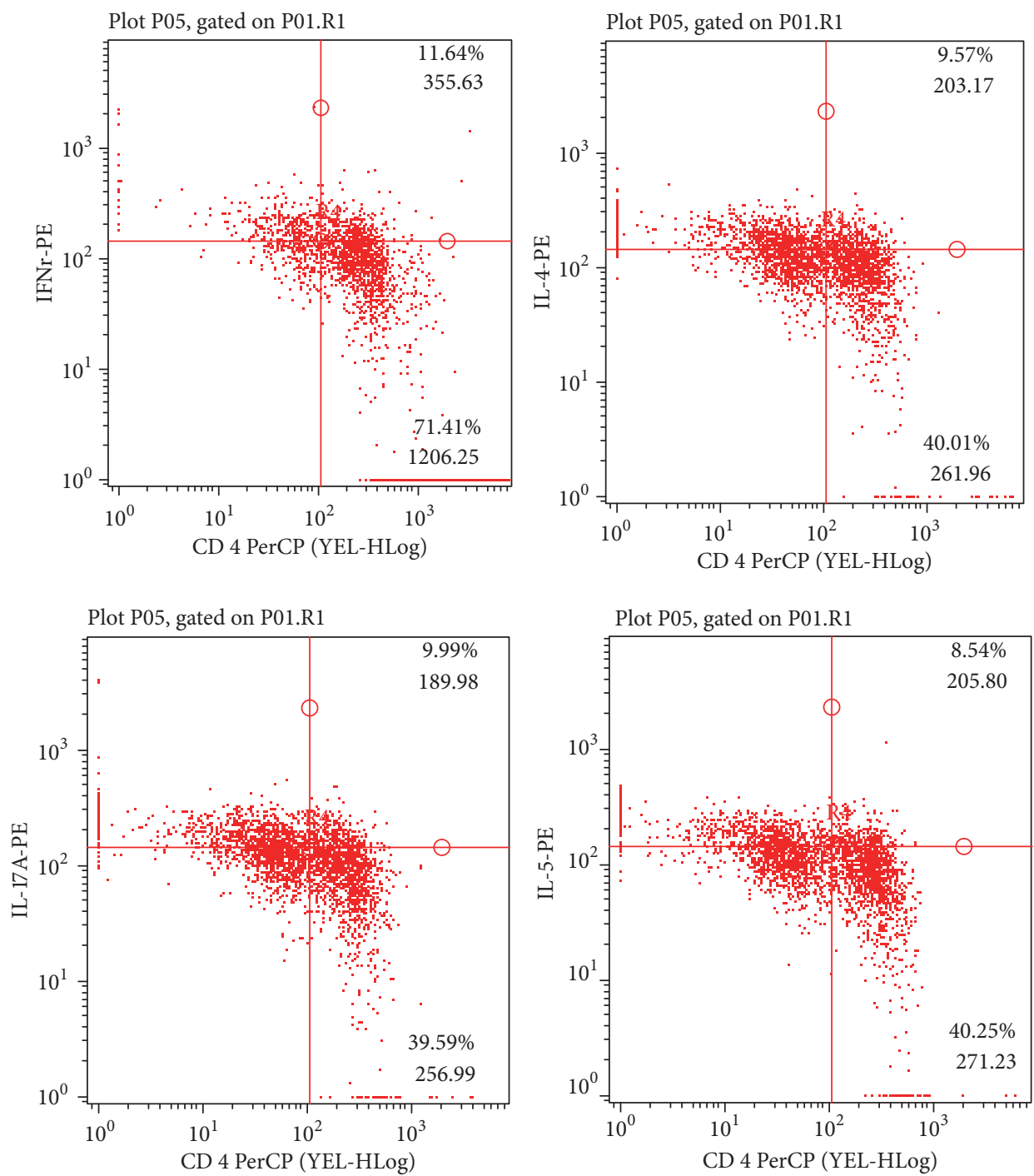

(b)

FIGURE 2: Elevated CD4 ${ }^{+} \mathrm{T}_{\mathrm{H}} 1$ (IFN- $\gamma$ ), $\mathrm{T}_{\mathrm{H}} 2$ (IL-4 and IL-5), and $\mathrm{T}_{\mathrm{H}} 17$ (IL-17a) populations in human PBMC of KC patients versus healthy volunteers. Peripheral T cells were stimulated with $1 \mathrm{ng} / \mathrm{ml} \mathrm{PMA}, 1 \mu \mathrm{M}$ ionomycin, and $3 \mu \mathrm{M}$ monensin. Intracellular staining (FACS) was done after 6 hours. Some representative FACS plots are given in (b). 


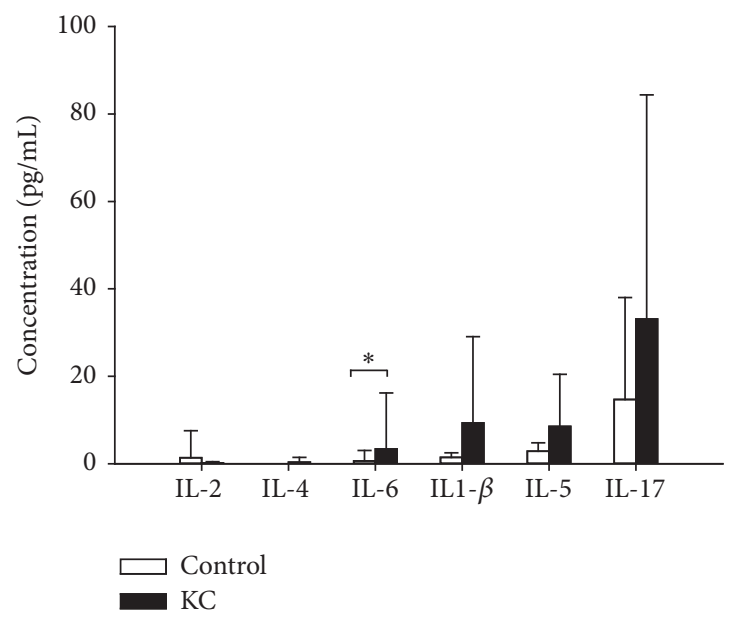

(a)

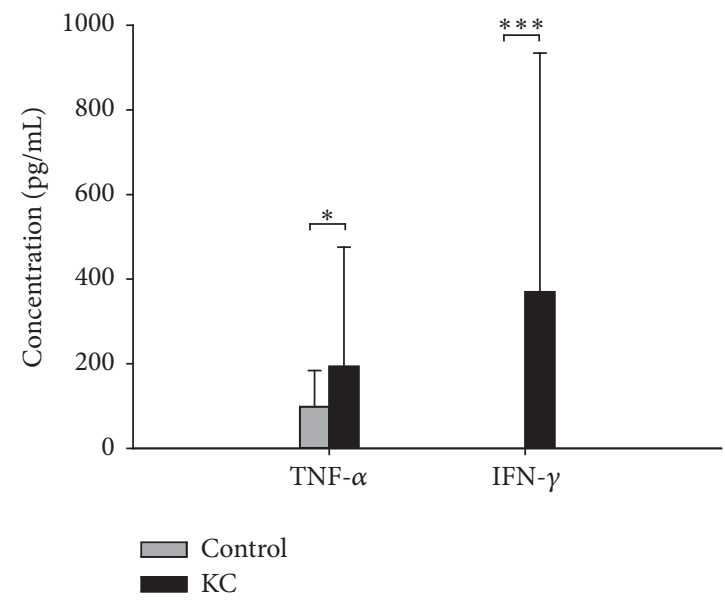

(b)

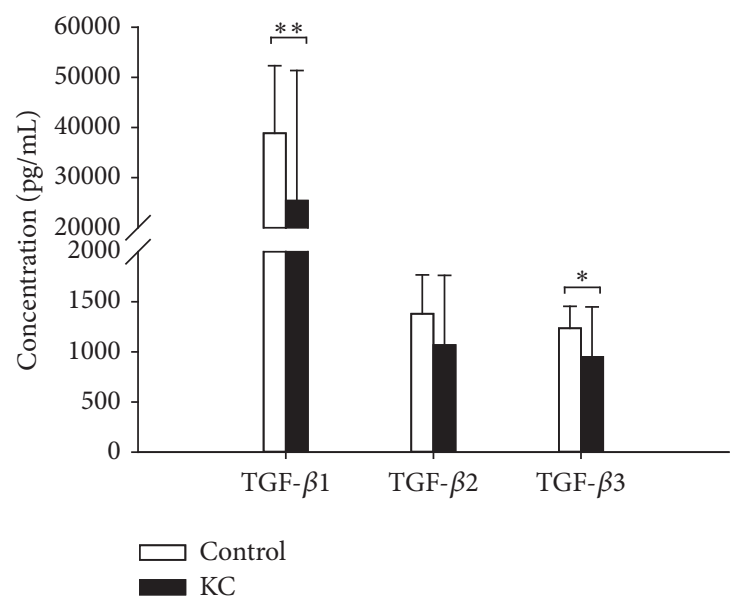

(c)

FIGURE 3: Effects of ketamine on inflammatory cytokines production by serum cytokine analysis. Data are expressed as mean \pm SD, where $n=27$. KC patient shows significantly higher concentrations of cytokines IL- 6 (a), TNF- $\alpha$, IFN- $\gamma$ (b) and significantly lower concentrations of TGF- $\beta 1$ and TGF- $\beta 3$ (c). ${ }^{*} P<0.05,{ }^{* *} P<0.01$, and ${ }^{* * *} P<0.001$.

paracrine may stimulate the $\mathrm{T}_{\mathrm{H}} 1$ cells to secrete their own lymphokines TNF- $\alpha$, IFN- $\gamma$, and IL-6 (Figure 3(b)). The IL-6, combined with TGF- $\beta$ and IL- $1 \beta$, induces the differentiation of $\mathrm{T}_{\mathrm{H}} 17$ from naïve cells and then enhances the IL-17 secretion (Figure 3(a)). IL-6 is an important switch that determines whether $\mathrm{T}_{\mathrm{H}} 17$ or $\mathrm{T}_{\mathrm{REG}}$ cells are generated when TGF- $\beta$ is present; TGF- $\beta 1$ has been known to inhibit the differentiation of $\mathrm{T}_{\mathrm{H}} 1$ and $\mathrm{T}_{\mathrm{H}} 2$ cells $[19,20]$. Hence, increases in IL- 6 and IL$1 \beta$ noted in KC patients may cause an offsetting response to the increase in TGF- $\beta 1$, TGF- $\beta 2$, and TGF- $\beta 3$ (Figures $3(\mathrm{a}$ ) and $3(\mathrm{c}))$. IL- 6 and IL-1 $\beta$ have been found to be increased in inflammatory urinary tract disease, indicating that IL-6 may also play an essential role in bladder dysfunction related to urinary tract infection [21].

IL-6 is a multifunctional cytokine which is produced at sites of tissue inflammation. It has been demonstrated that IL- 6 derived from APCs is able to initiate IL- 4 production in naive $\mathrm{CD} 4^{+} \mathrm{T}$ cells, thereby polarizing these cells into $\mathrm{T}_{\mathrm{H}} 2$ cells [22]. IL-4 targets B cells and mast cells, resulting in the production of IgE and inhibits IL-6 production; IL-5 targets eosinophils. The increased IFN- $\gamma$ may induce differentiation of $\mathrm{CD}^{+}$cells into $\mathrm{T}_{\mathrm{H}} 1$ cells and suppress the proliferation of $\mathrm{T}_{\mathrm{H}} 2$ cells, causing apoptosis of eosinophils and inhibiting $\operatorname{IgE}$ production [23]. Our results showed that both the eosinophil counts (Table 1) and IgE (Table 2) in KC patients were higher than that of normal laboratory values. Increased $\mathrm{T}_{\mathrm{H}} 2$ related cytokines, IL-4 and IL-5, were also found in KC patients, although there was no significant difference when compared to the normal control group (Figure $3(\mathrm{a})$ ). The $\mathrm{T}_{\mathrm{H}} 2$ cells also inhibit the development and function of $\mathrm{T}_{\mathrm{H}} 17$ and $\mathrm{T}_{\mathrm{H}} 1$ cells by means of their signature cytokine IL-4 [22]. These results demonstrated that IL-6 signaling has the ability to enhance the production of $\mathrm{T}_{\mathrm{H}} 2$ related cytokines (i.e., IL- 4 and IL5) via CD4+ T cell pathway. As regards $K C$ disease, a strong correlation between the frequencies of IL-17, TNF- $\alpha$, and IFN- $\gamma$ in KC patients has been observed (Figure 4). Previous studies have indicated that TNF- $\alpha$ and IL-17 have synergistic effects with many other factors, including IL- $1 \beta$, IL-22, and IFN- $\gamma$ [24]. The infiltrations of $\mathrm{T}_{\mathrm{H}} 1$ and $\mathrm{T}_{\mathrm{H}} 17$ cells have been associated with the pathogenesis of autoimmune disorders. 

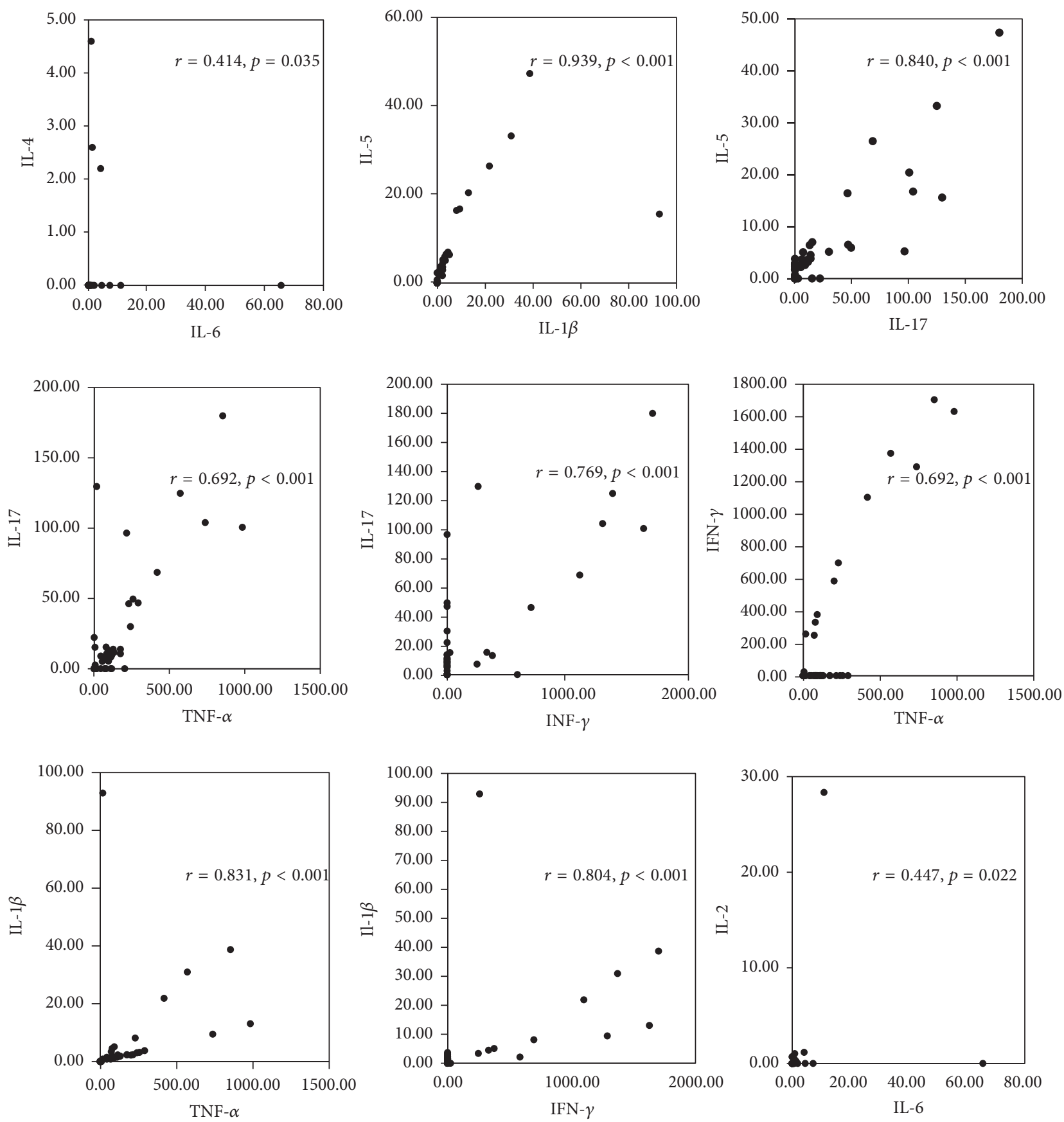

FIGURE 4: Correlation between various circulating cytokines in patients with ketamine cystitis.

$\mathrm{T}_{\mathrm{H}} 17$ effector cells are induced in parallel to $\mathrm{T}_{\mathrm{H}} 1$, and, like $T_{H} 1$, polarized $T_{H} 17$ cells have the capacity to induce inflammation and autoimmune disease [16]. The main function of IL-17-secreting T cells is to mediate inflammation, by stimulating production of inflammatory cytokines that promote the recruitment of neutrophils and macrophages [25]. Although we observed elevated IL-1 $\beta$ levels, the reduction of TGF- $\beta$ is consistent with the elevation of IL- 6 and IL-17 and may reflect $T_{H} 17$ cell activity rather than $T_{R E G}$ cell activity. In addition, the elevated levels of $\mathrm{T}_{\mathrm{H}} 2$ cells and their associated effector cytokines, IL-5, were correlated with
IL-1 $\beta$ and IL-17, indicating a central role for $\mathrm{T}_{\mathrm{H}} 17$-mediated immune responses associated with IL-6; IL- 6 promotes $\mathrm{T}_{\mathrm{H}} 17$ but suppresses $\mathrm{T}_{\mathrm{REG}}$ differentiation in $\mathrm{KC}$ disease [26]. Since the IL-5 and IL-17A regulate the production of specific-IgE in vivo [27], these results may explain the reason of increased IgE level and also can convince the eosinophil infiltration in the bladder suburothelium that was found in KC patients.

Study limitations include small sample size and the single time point serum measurement. The increased cytokine levels in KC patients reflect that the ongoing bladder inflammation noted at the bladder ulcer site is to be confirmed by further 


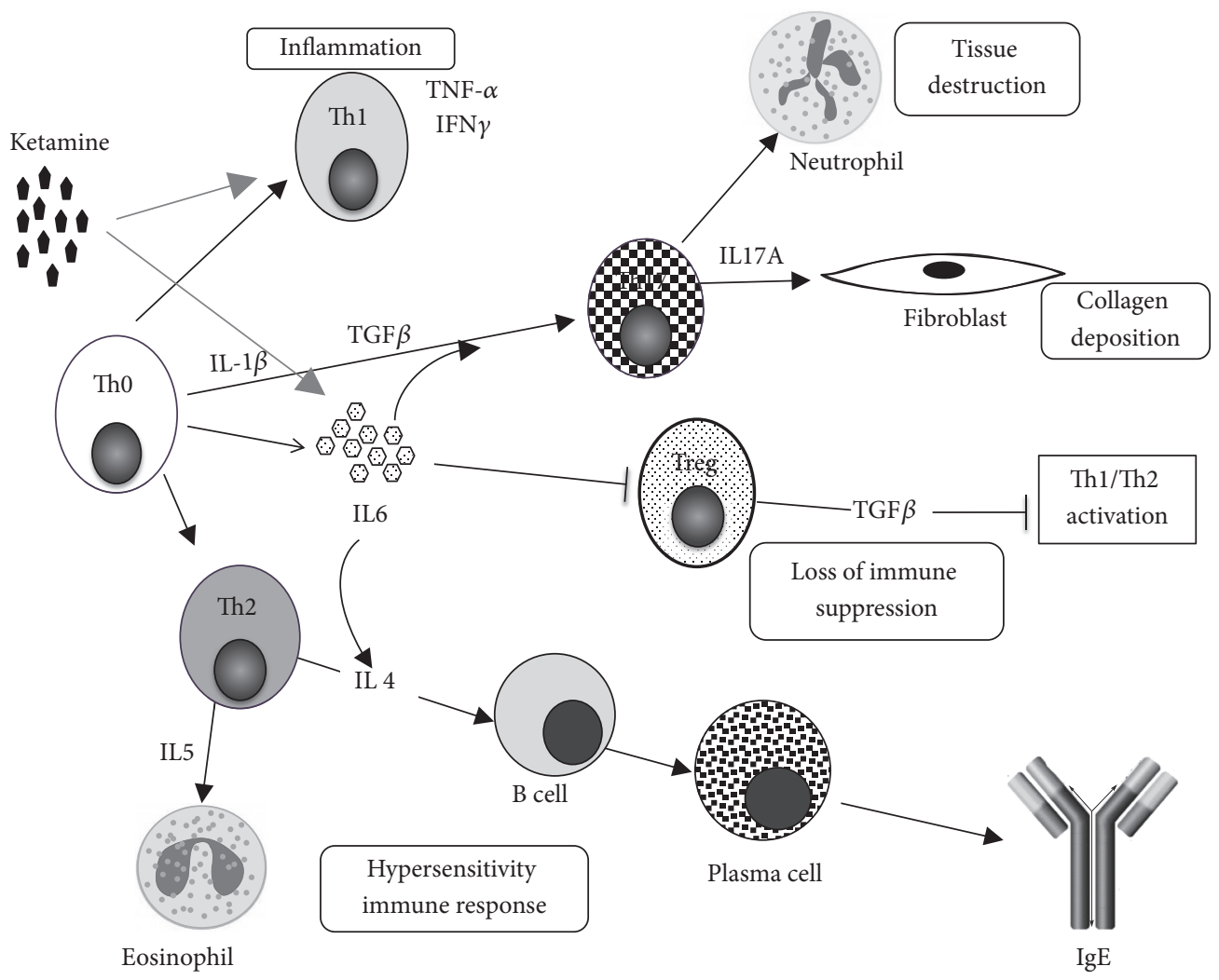

FIGURE 5: Schematic representation for the relationship between $\mathrm{T}$ cell pathways and their effector cytokines in ketamine cystitis patients. Ketamine may cause acute inflammation through $\mathrm{T}_{\mathrm{H}} 1$ pathway. Ketamine may also promote IL- 6 generation which links to the generation or maintenance of $\mathrm{T}_{\mathrm{H}} 17$ cell effector functions and then causes tissue destruction and collagen deposition. IL-6 promotes the differentiation of $\mathrm{T}_{\mathrm{H}} 2$ cells by enhancing endogenous IL- 4 production and increases the production of IgE. IL- 6 may also suppress $\mathrm{T}_{\mathrm{REG}}$ cells and therefore sustain the activation of $\mathrm{T}_{\mathrm{H}} 1$ and $\mathrm{T}_{\mathrm{H}} 2$ cells. Reinforced feedback of IL- 6 increases the production of IL-1 $\beta$ and IL-17 from CD4+ T cells.

investigation. Further investigation is necessary to clarify the role of IL-6 in $\mathrm{T}_{\mathrm{H}} 1 / \mathrm{T}_{\mathrm{H}} 2 / \mathrm{T}_{\mathrm{H}} 17$-regulated signaling pathway in ketamine-induced cystitis. These preliminary results pieced together from data collected from ketamine patients offer a possible mechanism of ketamine-associated cystitis. However, further in vivo tests would confirm the effects of various cytokine concentrations on $\mathrm{T}$ cell differentiation, particularly the initial concentrations of TGF- $\beta$ and IL-6. In vivo experiments would also allow us to control the daily amount of ketamine and the bladder could be analyzed at various stages of the inflammatory response to confirm our theory.

\section{Conclusion}

Ketamine may cause acute inflammation through $\mathrm{T}_{\mathrm{H}} 1$ pathway and elicit secondary mediator IL- 6 generation which links to the dynamic balance of $\mathrm{T}_{\mathrm{H}} 17 / \mathrm{T}_{\mathrm{REG}}$ cell effector functions. The IL- 6 may cause tissue destruction and collagen deposition via $T_{H} 17$ cells activation and suppress $T_{R E G}$ cells resulting in sustained activation of $\mathrm{T}_{\mathrm{H}} 1$ and $\mathrm{T}_{\mathrm{H}} 2$ cells. Further, the IL- 6 may promote the differentiation of $\mathrm{T}_{\mathrm{H}} 2$ cells by enhancing endogenous IL- 4 production and increase the production of IgE in KC patients. This is associated with $\mathrm{T}_{\mathrm{H}}$ 2-mediated chronic inflammatory response. In addition, the low concentration of TGF- $\beta 3$ in KC patients implied a suppression of $\mathrm{T}_{\mathrm{REG}}$ function, which may cause the tissue damage and immune-mediated inflammation. This will subsequently impair the healing of urothelium in KC patients.

\section{Ethical Approval}

This study was approved by the Institutional Review Board, Ministry of Science and Technology, National Defense Medical Center, Veterans General Hospital, and Tri-Service General Hospital, Taipei, Taiwan. There was no patient identifying information included in this manuscript. All the study subjects were strictly adhered to the Declaration of Helsinki 2012.

\section{Conflicts of Interest}

The authors declare that there are no conflicts of interest regarding the publication of this paper.

\section{Authors' Contributions}

En Meng and Juin-Hong Cherng were involved in the conception and design of the experiments. Gang-Yi Fan, JuinHong Cherng, Shu-Jen Chang, Raju Poongodi, Adrienne Chang, Sheng-Tang $\mathrm{Wu}$, and En Meng were involved in the 
collection, analysis, and interpretation of data. Juin-Hong Cherng, Raju Poongodi, and En Meng drafted the article.

\section{Acknowledgments}

This study was supported by the Ministry of Science and Technology (Grant nos. 103-2314-B-016-035-MY2 and 1052314-B-016-010); National Defense Medical Center (Grant nos. MAB-105-095 and MAB-106-051); Tri-Service General Hospital, Taipei Veterans General Hospital Joint Research Program (Grant no. DV104-13); Tri-Service General Hospital, Taiwan (Grant nos. TSGH-C104-056, TSGH-105-050, and TSGH-C106-042).

\section{References}

[1] C. C. K. Ho, H. Pezhman, S. Praveen et al., "Ketamine-associated ulcerative cystitis: A case report and literature review," Malaysian Journal of Medical Sciences, vol. 17, no. 2, pp. 61-65, 2010.

[2] S. M. Green, M. G. Roback, R. M. Kennedy, and B. Krauss, "Clinical practice guideline for emergency department ketamine dissociative sedation: 2011 update," Annals of Emergency Medicine, vol. 57, no. 5, pp. 449-461, 2011.

[3] D. Wood, A. Cottrell, S. C. Baker et al., "Recreational ketamine: From pleasure to pain," BJU International, vol. 107, no. 12, pp. 1881-1884, 2011.

[4] E. Meng, S.-T. Wu, T.-L. Cha, G.-H. Sun, D.-S. Yu, and S.-Y. Chang, "A murderer of young bladders: Ketamine-associated cystitis," Urological Science, vol. 24, no. 4, pp. 113-116, 2013.

[5] S. Middela and I. Pearce, "Ketamine-induced vesicopathy: A literature review," International Journal of Clinical Practice, vol. 65, no. 1, pp. 27-30, 2011.

[6] P. S.-K. Chu, W.-K. Ma, S. C.-W. Wong et al., "The destruction of the lower urinary tract by ketamine abuse: A new syndrome?" BJU International, vol. 102, no. 11, pp. 1616-1622, 2008.

[7] E. Meng, "Ketamine cystitis-A long-lasting burning issue in Taiwan," Urological Science, vol. 26, no. 3, pp. 158-159, 2015.

[8] H.-C. Lin, H.-S. Lee, T.-S. Chiueh et al., "Histopathological assessment of inflammation and expression of inflammatory markers in patients with ketamine-induced cystitis," Molecular Medicine Reports, vol. 11, no. 4, pp. 2421-2428, 2015.

[9] T.-H. Tsai, T.-L. Cha, C.-M. Lin et al., "Ketamine-associated bladder dysfunction: Original Article," International Journal of Urology, vol. 16, no. 10, pp. 826-829, 2009.

[10] J.-F. Jhang, Y.-H. Hsu, Y.-H. Jiang, and H.-C. Kuo, "Elevated serum IgE may be associated with development of ketamine cystitis," The Journal of Urology, vol. 192, no. 4, pp. 1249-1256, 2014.

[11] P. Kidd, "Th1/Th2 balance: the hypothesis, its limitations, and implications for health and disease," Alternative Medicine Review, vol. 8, no. 3, pp. 223-246, 2003.

[12] N. Qu, M. Xu, and I. Mizoguchi, "Pivotal roles of T-helper 17-related cytokines, IL-17, IL-22, and IL-23, in inflammatory diseases," Clinical and Developmental Immunology, vol. 2013, Article ID 968549, 13 pages, 2013.

[13] G. E. Kaiko, J. C. Horvat, K. W. Beagley, and P. M. Hansbro, "Immunological decision-making: how does the immune system decide to mount a helper T-cell response?" The Journal of Immunology, vol. 123, no. 3, pp. 326-338, 2008.
[14] G. Kaplanski, V. Marin, F. Montero-Julian, A. Mantovani, and C. Farnarier, "IL-6: a regulator of the transition from neutrophil to monocyte recruitment during inflammation," Trends in Immunology, vol. 24, no. 1, pp. 25-29, 2003.

[15] S. H. Kim, J. Turnbull, and S. Guimond, "Extracellular matrix and cell signalling: the dynamic cooperation of integrin, proteoglycan and growth factor receptor," Journal of Endocrinology, vol. 209, no. 2, pp. 139-151, 2011.

[16] E. M. Eisenstein and C. B. Williams, "The Treg/Th17 cell balance: A new paradigm for autoimmunity," Pediatric Research, vol. 65, no. 5, 2009.

[17] T. Riaz, L. M. Sollid, I. Olsen, and G. A. De Souza, "Quantitative proteomics of gut-derived Th1 and Th1/Th17 clones reveal the presence of CD28+ NKG2D-Th1 cytotoxic CD4+ T cells," Molecular \& Cellular Proteomics, vol. 15, no. 3, pp. 1007-1016, 2016.

[18] D. De Groote, P. F. Zangerle, Y. Gevaert et al., "Direct stimulation of cytokines (IL- $1 \beta$, TNF- $\alpha$, IL-6, IL-2, IFN- $\gamma$ and GM-CSF) in whole blood. I. Comparison with isolated PBMC stimulation," Cytokine, vol. 4, no. 3, pp. 239-248, 1992.

[19] B. R. Ludviksson, D. Seegers, A. S. Resnick, and W. Strober, "The effect of TGF- $\beta 1$ on immune responses of naive versus memory CD4+ Th1/Th2 T cells," European Journal of Immunology, vol. 30, no. 7, pp. 2101-2111, 2000.

[20] J. Scheller, A. Chalaris, D. Schmidt-Arras, and S. Rose-John, "The pro- and anti-inflammatory properties of the cytokine interleukin-6," Biochimica et Biophysica Acta (BBA) - Molecular Cell Research, vol. 1813, no. 5, pp. 878-888, 2011.

[21] C.-C. Wang, T.-I. Weng, E.-T. Wu, M.-H. Wu, R.-S. Yang, and S.-H. Liu, "Involvement of interleukin-6-regulated nitric oxide synthase in hemorrhagic cystitis and impaired bladder contractions in young rats induced by acrolein, a urinary metabolite of cyclophosphamide," Toxicological Sciences, vol. 131, no. 1, pp. 302-310, 2013.

[22] M. Rincón, J. Anguita, T. Nakamura, E. Fikrig, and R. A. Flavell, "Interleukin (IL)-6 directs the differentiation of IL-4-producing CD4+ T cells," The Journal of Experimental Medicine, vol. 185, no. 3, pp. 461-469, 1997.

[23] J. R. Schoenborn and C. B. Wilson, "Regulation of interferon$\gamma$ during innate and adaptive immune responses," Advances in Immunology, vol. 96, pp. 41-101, 2007.

[24] R. M. Onishi and S. L. Gaffen, "Interleukin-17 and its target genes: mechanisms of interleukin-17 function in disease," The Journal of Immunology, vol. 129, no. 3, pp. 311-321, 2010.

[25] K. H. G. Mills, "Induction, function and regulation of IL-17producing T cells," European Journal of Immunology, vol. 38, no. 10, pp. 2636-2649, 2008.

[26] S. G. Zheng, "Regulatory T cells vs Th17: differentiation of Th17 versus Treg, are the mutually exclusive?" American Journal of Clinical and Experimental Immunology, vol. 2, no. 1, pp. 94-106, 2013.

[27] L. Z. Grund, E. N. Komegae, M. Lopes-Ferreira, and C. Lima, "IL-5 and IL-17A are critical for the chronic IgE response and differentiation of long-lived antibody-secreting cells in inflamed tissues," Cytokine, vol. 59, no. 2, pp. 335-351, 2012. 


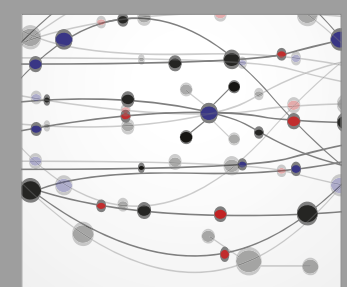

The Scientific World Journal
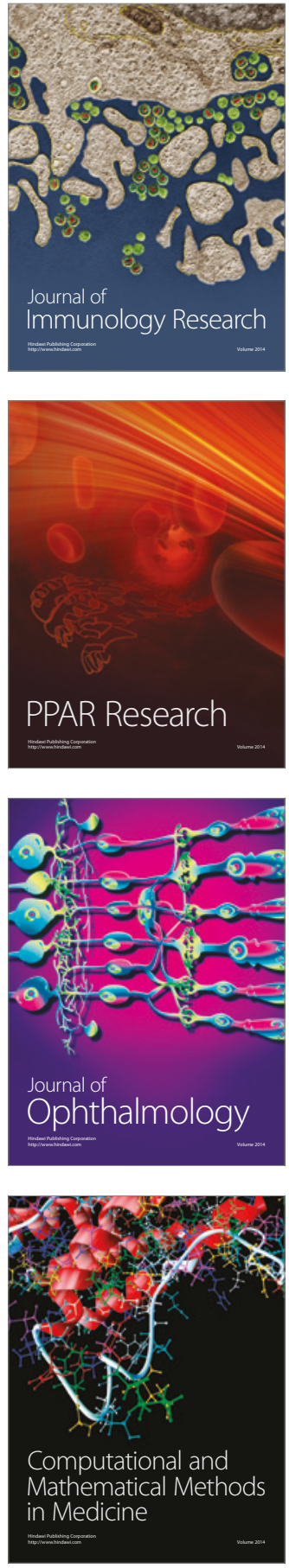

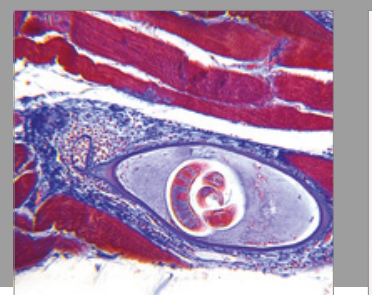

Gastroenterology Research and Practice
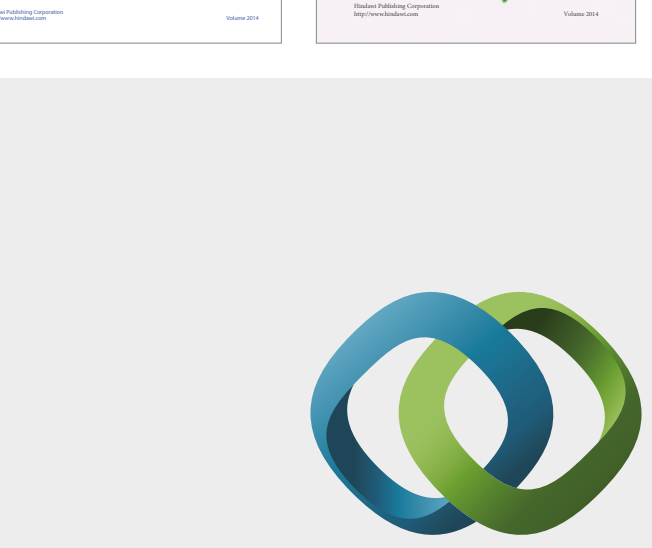

\section{Hindawi}

Submit your manuscripts at

https://www.hindawi.com
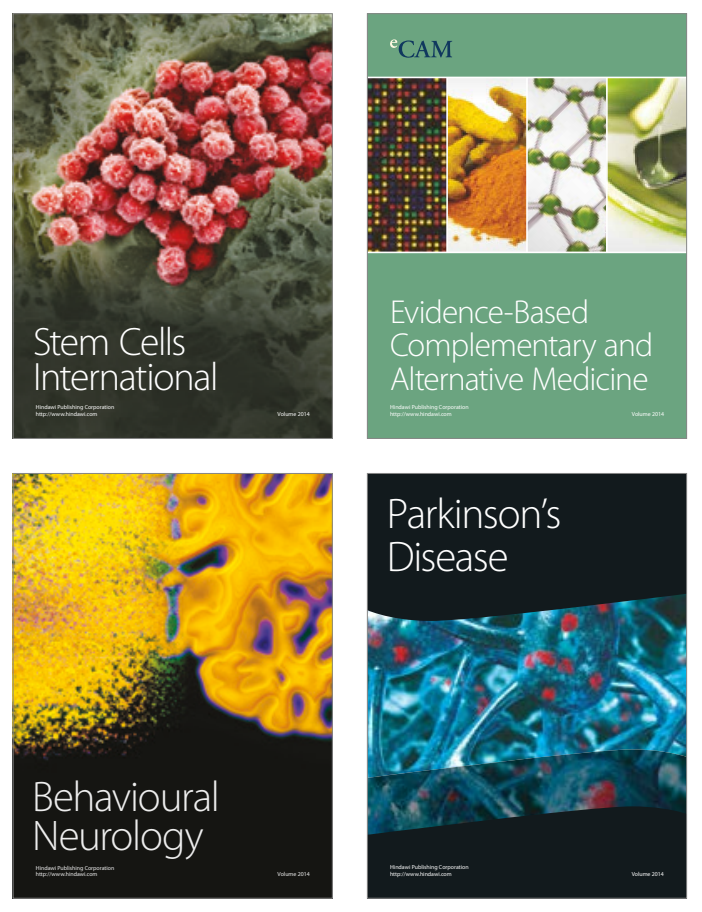
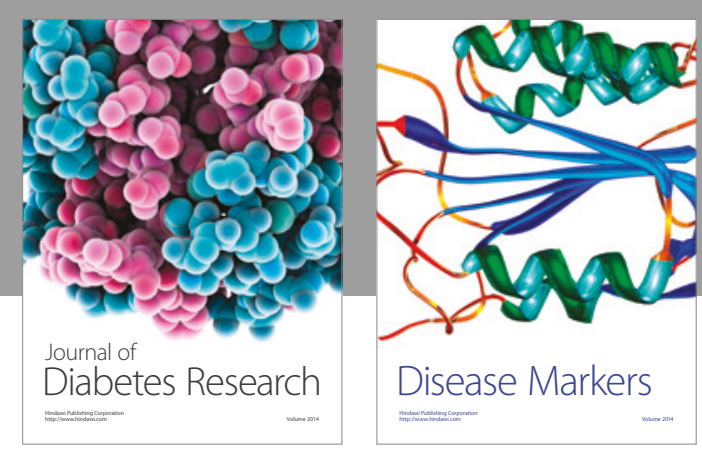

Disease Markers
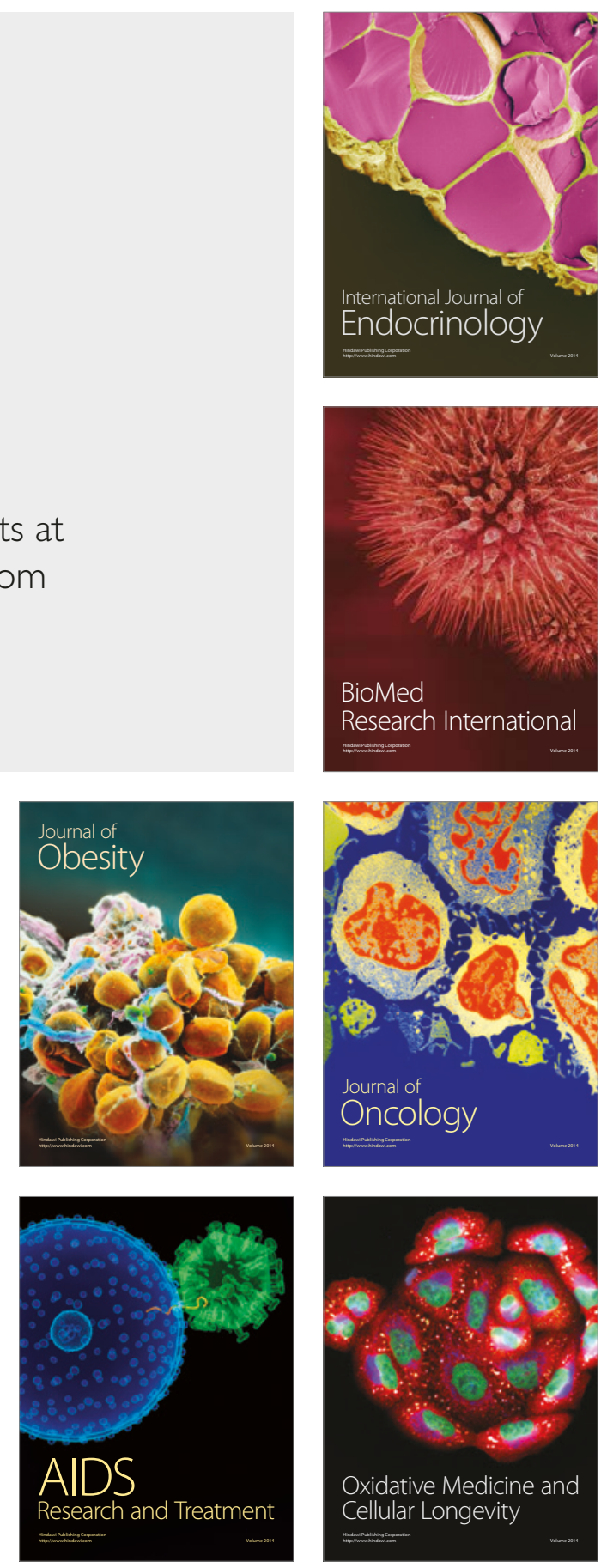